\title{
USDA
}

United States Department of Agriculture

Northern Forests Cilmate Hib

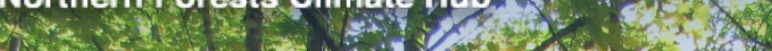
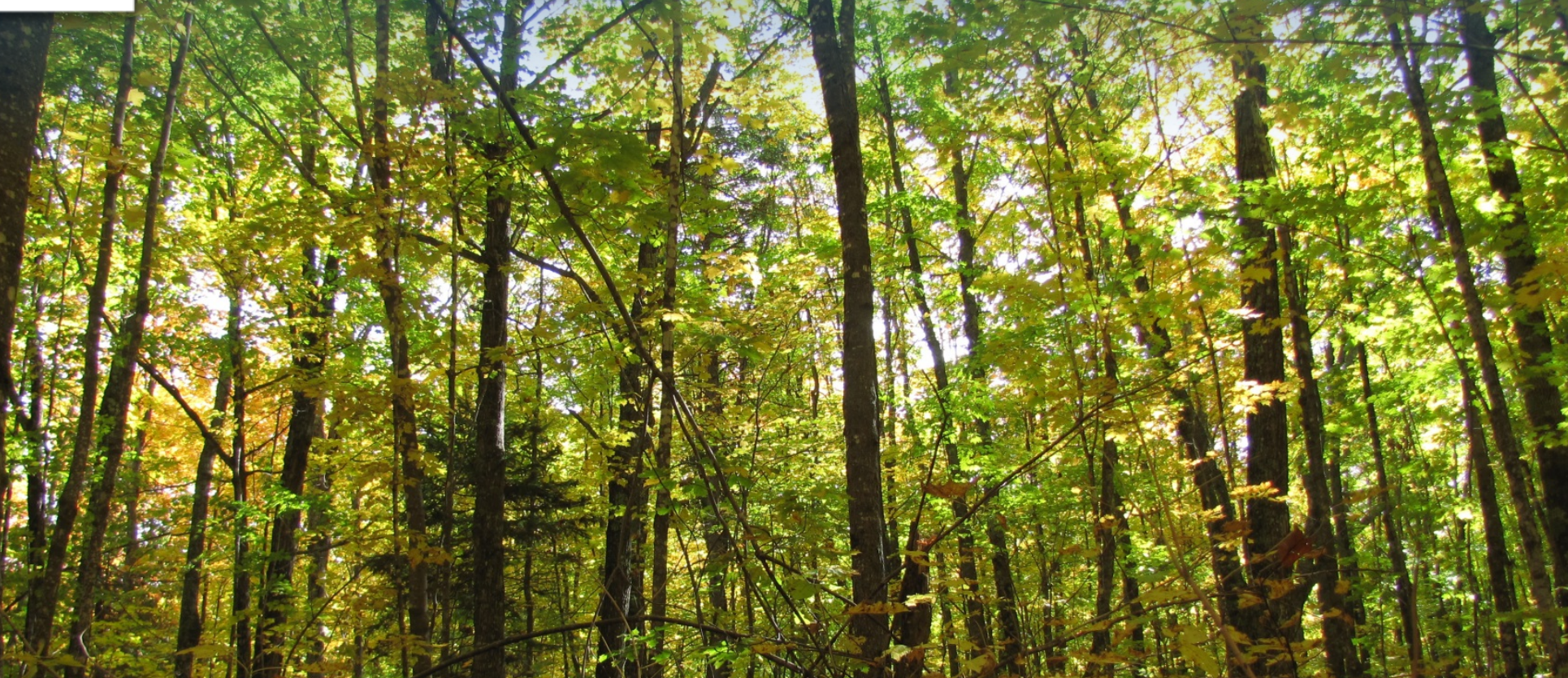

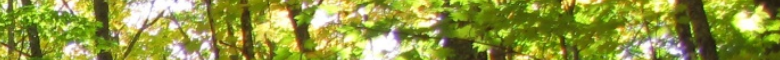

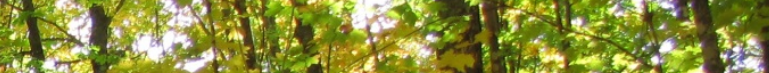

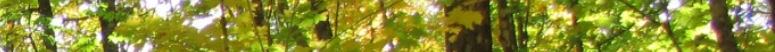

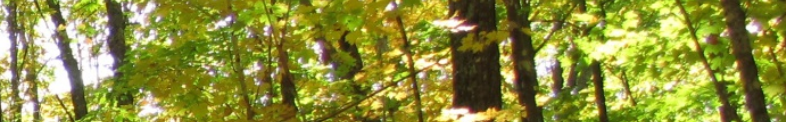
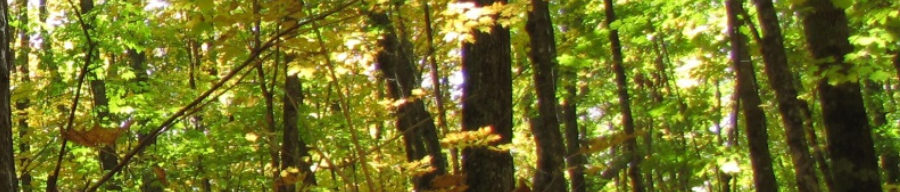

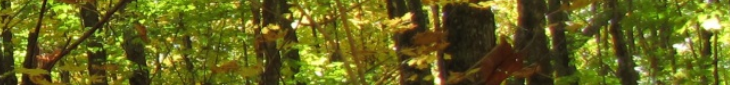

the

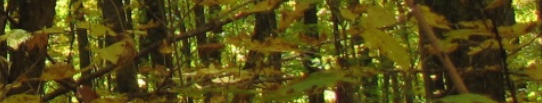

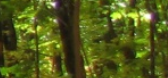

2016

\section{FINDING OPPORTUNITIES WITHIN USDA PROGRAMS TO REDUCE GHG EMISSIONS AND INCREASE CARBON SEQUESTRATION}

USDA NORTHERN FORESTS CLIMATE HUB \& THE FOREST-CLIMATE WORKING GROUP 


\section{CONTENTS}

EXECUTIVE SUMMARY

INTRODUCTION \& WORKSHOP CONTEXT 2

CONTEXT OF USDA PROGRAMS

WORKSHOP RESULTS

\section{PERSPECTIVES FROM THE FIELD: SUMMARY OF WORKSHOP 1}

1. Defining management goals.

2. Partnerships and coordination.

3. Encouraging innovation and demonstrations.

4. Developing guidance.

5. Improving carbon accounting protocols and database systems.

6. Providing incentives.

FINDING USDA PROGRAMMATIC GHG MITIGATION OPPORTUNITIES: $\quad 7$ SUMMARY OF WORKSHOP 2

1. Develop a baseline inventory of where carbon is explicitly included in USDA 8 Programs.

2. Increase the exchange of knowledge between science and land management 8 communities to create more "usable science" on mitigation.

3. Finalize an Agricultural Adaptation Workbook that walks managers through 8 climate-informed decision-making.

4. Incorporate carbon sequestration and storage into relevant USDA program guidance, such as NRCS conservation practice standards and USFS State and Private Forestry programs.

\section{PREPARED BY}

USDA Northern Forests

Climate Hub

Chris Swanston

Northern Institute of Applied

Climate Science

US Forest Service

\section{Kristen Schmitt}

Northern Institute of Applied

Climate Science

\section{Danielle Shannon}

Northern Institute of Applied Climate Science

\section{Forest-Climate Working} Group

Jad Daley

Trust for Public Land

5. For all Building Blocks, run an analysis on enhanced GHG reduction and carbon sequestration goals for 2025.

6. Increase the presence of forestry and land management in competitive research.

7. Develop communications pieces that link conservation needs with carbon numbers.

8. Make carbon sequestration a more explicit objective of forest management.

9. Use NRCS and USFS projects as demonstrations of a climate-informed management approach.

10. Develop a better understanding of the relationship between climate and forest soil carbon.

11. Engage third-party market opportunities via cost share. 12

12. Develop a "no net forest loss" policy.

\section{INTEGRATION OF THEMES BETWEEN WORKSHOPS $1 \& 2$}

1. Define the carbon connections and management goals within USDA programs and communicate these effectively.

2. Incentivize and develop science-supported guidance on reducing GHG emissions and increasing carbon sequestration in the field.

3. Develop communication tools and policies to support public-private partnerships on carbon management.

4. Encourage innovation and demonstrations. 


\section{EXECUTIVE SUMMARY}

The USDA Northern Forests Climate Hub (NFCH) and the Forest-Climate Working Group (FCWG) held a series of two workshops designed to identify specific opportunities within USDA programs to explicitly support greenhouse gas mitigation in the forest sector. The first workshop (Perspectives from the Field) gathered suggestions and ideas from field practitioners familiar with using USDA programs to support forest carbon benefits. The second workshop (Finding USDA Programmatic GHG Mitigation Opportunities) invited USDA Program leads and representatives to develop specific suggestions on modifications to USDA Programs that could assist in these efforts. The final outcome was a series of twelve ideas from USDA Program leads and representatives that took into account input from the field, and outlined specific needs for each idea. These twelve are listed below and summarized more completely in the Workshop summary section description ( $p$ 7).

\section{PROGRAM ADJUSTMENT}

1. Develop a baseline inventory of where carbon is explicitly included in USDA Programs.

2. Increase the exchange of knowledge between science and land management communities to create more "usable science" on mitigation.

3. Finalize an Agricultural Adaptation Workbook that walks managers through climate-informed decisionmaking.

\section{PROGRAM ADJUSTMENT/OPTIMIZATION}

4. Incorporate carbon sequestration and storage into relevant USDA program guidance, such as NRCS Conservation Practice Standards and USFS State and Private Forestry programs.

5. For all Building Blocks, run an analysis on enhanced GHG reduction and carbon sequestration goals for 2025.

\section{PROGRAM OPTIMIZATION}

6. Increase the presence of forestry and land management in competitive research.

7. Develop communications pieces that link conservation needs with carbon numbers.

8. Make carbon sequestration a more explicit objective of forest management.

9. Use NRCS and USFS projects as demonstrations of a climate-informed management approach.

\section{PROGRAM REALIGNMENT}

10. Develop a better understanding of the relationship between climate and forest soil carbon.

11. Engage third-party market opportunities via cost share.

12. Develop a "No net forest loss" policy. 


\section{INTRODUCTION \& WORKSHOP CONTEXT}

The USDA Building Blocks for Climate Smart Agriculture and Forestry were developed in support of the president's commitment to mitigate greenhouse gases (GHGs). The USDA Northern Forests Climate Hub (NFCH) and the Forest-Climate Working Group (FCWG) have jointly committed to support the Building Blocks by helping to identify opportunities within USDA programs to explicitly support GHG mitigation. In the spring and summer of 2016, the NFCH and FCWG developed two workshops to engage USDA field personnel and USDA leadership in problem-solving discussions related to the application of forest carbon management in USDA programs and policies.

The initial "Perspectives from the Field" workshop gathered feedback from innovative practitioners and early adopters who had experience or familiarity with using USDA programs for carbon benefits. This workshop was hosted in Chicago in March 2016, and attended by 24 people from across the country representing various sectors: USDA (Climate Hubs, Forest Service, and Natural Resources Conservation Service), States (PA, VT), Academia (eXtension, Michigan State University, Southern Regional Extension, Univ. of Rhode Island), NGOs (Forest Trends, New England Forestry, Placer Land Trust, Trust for Public Lands), and Private industry (AF\&PA, TerraCarbon LLC). Suggestions from this workshop were synthesized into a summary document (section IV.a.)

A second workshop (Finding GHG Mitigation Opportunities within USDA Programs) brought together 25 USDA Program leads and representatives in July 2016 to consider the feedback from the field, and to identify opportunities to adjust programs to better reduce greenhouse gas emissions and increase carbon sequestration. Representatives from NRCS, USFS (National Forest System, Research and Development, State and Private Forestry), USDA (National Institute of Food and Agriculture, Climate Change Program Office, Climate Hubs) and the Forest-Climate Working Group attended the meeting. Participants developed a list of 12 suggestions that ranged from small adjustments to USDA Programs to stronger modifications and additions. The suggestions from both workshops and key themes raised by both field personnel and program leads are summarized in this document.

\section{CONTEXT OF USDA PROGRAMS}

The workshops were framed by two dimensions of perceived opportunity to increase the carbon benefits of existing USDA programs. As one dimension of analysis, workshop participants were encouraged to consider the potential for federal programs to impact land-based carbon sinks in three ways: 1) Permanent conservation (avoided conversion of the forest system); 2) Restoration (repair of a damaged forest system or replanting forests where they had previously been cleared and the land converted to non-forest use); and 3) Stewardship (improved management of an existing forest system to increase carbon sequestration and storage while minimizing the loss of carbon due to forest stressors). These categories of activity are not clean or simple-some USDA programs in fact impact more than one of these activities-but the categories nevertheless provided a potentially helpful frame to think about the different ways that each USDA programs might impact carbon. Permanent conservation, restoration, and stewardship all have a direct relationship to improving the qualities of the carbon sink and its sequestration benefits through effects on the amount, timing, durability, and predictability as well as assuring that carbon gains will be compatible and harmonious with other objectives for land management.

The second dimension of analysis was to consider exactly how an existing USDA program might need to adjust, optimize, or even fundamentally realign to create additional carbon impact. Regardless of the annual funding levels provided, evaluating the administration of these programs by evaluating their levers for carbon impact offers potential to then prioritize investments and technical assistance to projects that will most significantly increase carbon. To accomplish this, workshop participants were encouraged to think about program adjustment, optimization, and realignment in three fundamental ways: 1) Changes to grant criteria and other program guidance that would prioritize carbon; 2) Region or activity-specific carve-out funding from overall program budgets to focus dollars on the highest carbon regions and project typologies; and 3) Incentivizing proposals that combine carbon beneficial actions across the three categories of activity (permanent conservation, restoration, and stewardship) and across multiple programs. 


\section{WORKSHOP RESULTS}

\section{PERSPECTIVES FROM THE FIELD: SUMMARY OF WORKSHOP 1}

The first workshop engaged innovative practitioners and early adopters from the field who had experience or familiarity with using USDA programs for carbon benefits. This workshop was hosted in Chicago in March 2016, and attended by 24 people from across the country representing various sectors: USDA (Climate Hubs, Forest Service, and Natural Resources Conservation Service), States (PA, VT), Academia (eXtension, Michigan State University, Southern Regional Extension, Univ. of Rhode Island), NGO (Forest Trends, New England Forestry, Placer Land Trust, Trust for Public Lands), and Private industry (AF\&PA, TerraCarbon LLC). Practitioners also identified program-supported opportunities to implement GHG mitigation actions, barriers to implementing these actions, and ideas for resolving challenges. Major themes from the workshop are summarized below.

\section{Defining carbon management goals.}

USDA programs could better establish a connection to carbon management with inclusion of explicit language, agency goals, and management criteria into programs and policies.
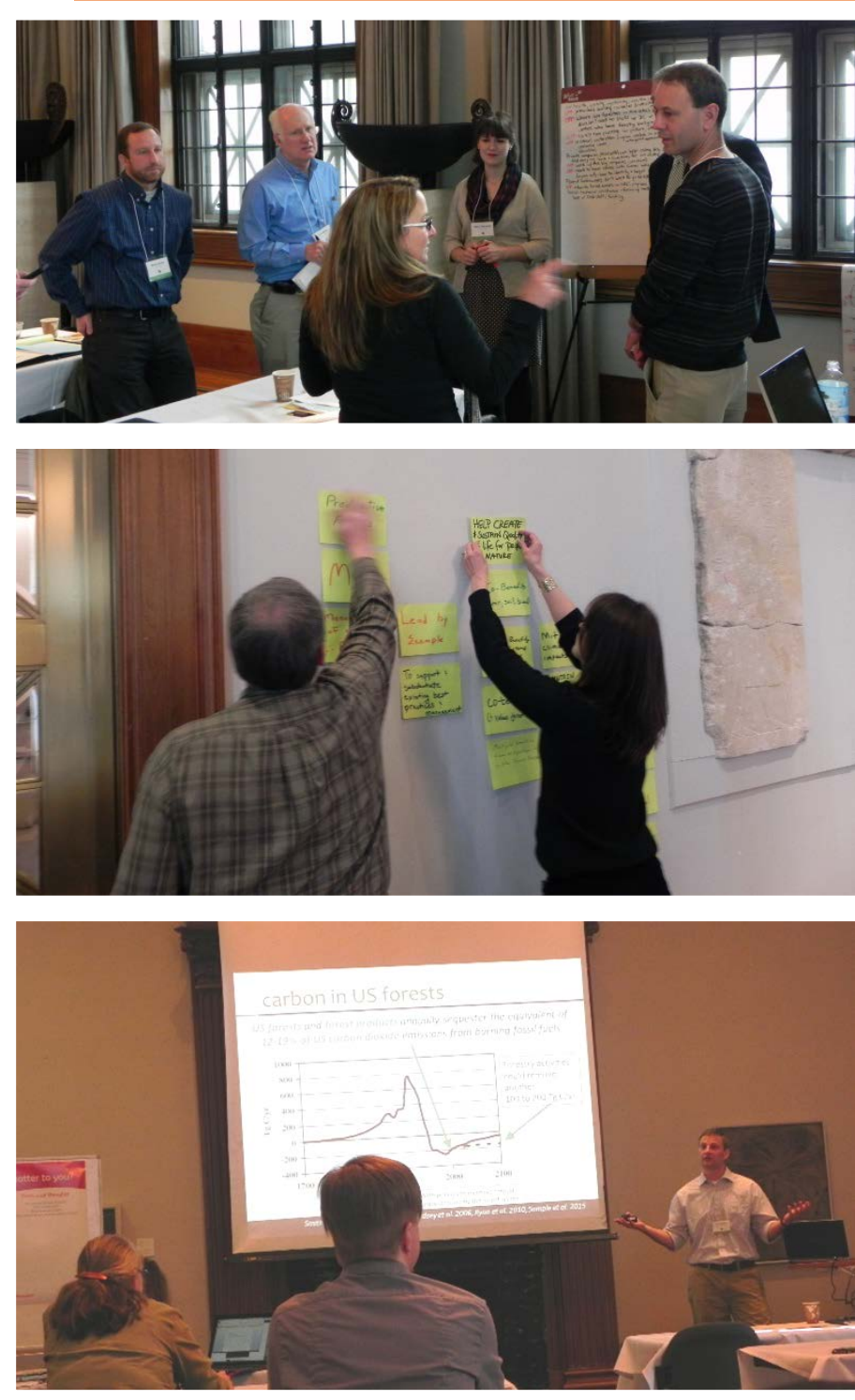

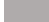

\section{SELECTED IDEAS AND SUGGESTIONS FROM THE} FIELD -

- Identify a USDA carbon point person in each agency to coordinate and facilitate integration of carbon goals and guidelines into programs.

- Set firm goals for carbon management and greenhouse gas mitigation within USDA programs and policies.

- Create carbon criteria and benchmarks specific to USDA programs. 


\section{Partnerships and coordination.}

USDA could further support public-private collaborations and partnerships related to carbon management on private and federal lands as well as in focused sectors like wood products and wood based energy generation. Expanding the partner network and engaging in new coordination efforts could emphasize and integrate advocacy and education. Partnershipbuilding would require agency-level facilitation between public and private industries, academia, nongovernmental organizations, and public agencies..

\section{Encouraging innovation and demonstrations.}

Participants indicated a need for USDA to "think outside of the box" and to encourage innovative approaches for forest sector GHG mitigation. Suggestions included using demonstration sites to pilot carbon management techniques, and encouraging creative applications of wood product and renewable energy resources. Investing in innovation also presents a wide range of communication and partnership opportunities.

\section{SELECTED IDEAS AND SUGGESTIONS FROM THE FIELD -}

- Convene diverse groups with mutual interests to facilitate initiatives to advocate and advance awareness of USDA programs, and policies.

- Better link and coordinate USDA programs with mutual landowner benefits, and provide direction on stacking funding between USDA agencies.

- Encourage creative coordination at the regional and landscape scale, such as coordinating wood supply chains between forest and energy industries to reduce upfront costs.

- Encourage federal agencies to link perspectives and efforts. For example, USDA could facilitate collaborations between an "energy" focused agency (DOE) and a "products" focused agency (FS) to find commonalities and opportunities to work together.

- Support partnerships to expand networks and increase likelihood of reaching carbon goals (such as: USDA agencies, academia, extension, state forestry divisions, California Air Resources Board, National Association of State Foresters, Southern group of state foresters, forest landowner associations, Tree Farm participants, SFI, US endowment apple seed program, and others) in silvicultural and stand management planning.

\section{SELECTED IDEAS AND SUGGESTIONS FROM THE FIELD -}

- Invest in demonstration sites to test management concepts on public and private lands (e.g. National Forests). Demonstration projects serve as useful long term learning opportunities and collaborative platforms encouraging diverse partnerships and advocacy initiatives.

- Coordinate efforts between USDA agencies to pilot and test innovative concepts.

- Test new and short-term incentive programs that change forest management directions through reverse auctions (e.g. management plans coupled with short term action requirement). 


\section{Developing guidance.}

There is a need for USDA to assess current guidance provided to foresters and natural resource managers related to carbon management protocols, accounting methodology, and silvicultural practices to support agency carbon goals. Education on carbon management and decision-making tools are needed for the USDA workforce (at all levels), and to help communicate the benefits of carbon management to private landowners and regional partners.
5. Improving carbon accounting protocols and database systems.

USDA has programs containing potential carbon benefits that could be quantified. If carbon benefits are accounted for within existing programs and policies, there are opportunities to coordinate and leverage carbon interests between USDA programs and with outside partners to incentivize actions on all lands.
SELECTED IDEAS AND SUGGESTIONS FROM THE FIELD -

- Quantify carbon benefits of specific silvicultural practices.

- Develop decision-making tools for managers to maximize carbon benefits.

- Define silvicultural planning guidelines for managers specific to carbon at the site level, such as defining and providing a list of best management practices related to 1) tree species that increase carbon, 2) age thresholds, 3) soil health, 4) invasive plants and pests, 5) long term monitoring measurements and techniques. Explicitly note characteristics of a stand, and management practices that may affect carbon potential.

- Devise a menu of carbon considerations for federal forest managers to consider in management of forests.

- Create guidance protocols describing the spectrum of carbon management considerations for field managers.

- Integrate carbon benefits of wood energy, products and infrastructure into guidance documents.

\section{SELECTED IDEAS AND SUGGESTIONS FROM THE FIELD -}

- Evaluate current accounting frameworks and define a required methodology for accounting across USDA agencies.

- Assess the robustness of current database systems and evaluate gaps. Improve database technology to aid data collection and digitization.

- Ensure sufficient and consistent information available at the forest stand level to help inform management planning and implementation. This work would ultimately strengthen silvicultural guidelines and future planning and monitoring efforts.

- Characterize carbon benefits and co-benefits of practices on forests and sensitive lands.

- Define an accounting framework for wood energy (in particular biofuels accounting). This tool would bolster efforts to include wood in clean power plans. 


\section{Providing incentives.}

There may be opportunities to further incentivize carbon management and GHG mitigation within each of the building block areas. Suggestions ranged from including carbon as a component of existing incentives, to incentivizing research and industry (e.g. small business innovation grants, implementation of sustainable building codes), to providing incentives to implement beneficial practices on private and federal lands. Further evaluation of USDA program integration into markets requires creative exploration to meet monitoring requirements (for verification).
SELECTED IDEAS AND SUGGESTIONS FROM THE FIELD -

- Provide strategies to sustain long term practices and enforce permanence of practices on private and public lands.

- Define criteria for generational land transfer programs.

- Include carbon practices in NRCS program ranking (timber improvements should rank higher).

- Incentivize private landowner carbon management to sustain long term management for carbon and associated co-benefits.

- Incentivize National Forests to implement carbon practices, consider competitive FS funding for innovative forest carbon activities.

- Incentivize early intervention (planting) in areas susceptible to disease/insect infestations (eg. underplanting in Ash forest prior to $E A B$ ).

- Incentivize best management practices for forest soil management.

- Invest in wood product and energy innovation by incentivizing small business innovation grants, investing in research, and evaluating building codes.

- Incentivize carbon by increasing the price point; this will help to ensure forest management is costeffective in the near term.

- Incentivize production of food and non-timber forest products within windbreaks and riparian buffers that provide protective functions. 


\section{WORKSHOP RESULTS}

\section{FINDING USDA PROGRAMMATIC GHG MITIGATION OPPORTUNITIES: SUMMARY OF WORKSHOP 2}

The second workshop invited USDA Program representatives to develop suggestions for improving the ability of USDA programs to explicitly support GHG mitigation in the forest sector. Participants were asked to think of options that ranged along a continuum from small program adjustments, to optimization, to larger program realignment (Figure 1).

Nearly all participants were ready and willing to consider this full range of possibilities. The majority felt that in an ideal world they would be working on full program realignment to better support GHG mitigation, however within the context of their current abilities and constraints, they could begin the process of optimizing programs (middle of the continuum).

Participants worked in small groups to develop 12 concrete ideas for USDA Programs that spanned the continuum (Figure 1), findings are summarized below.
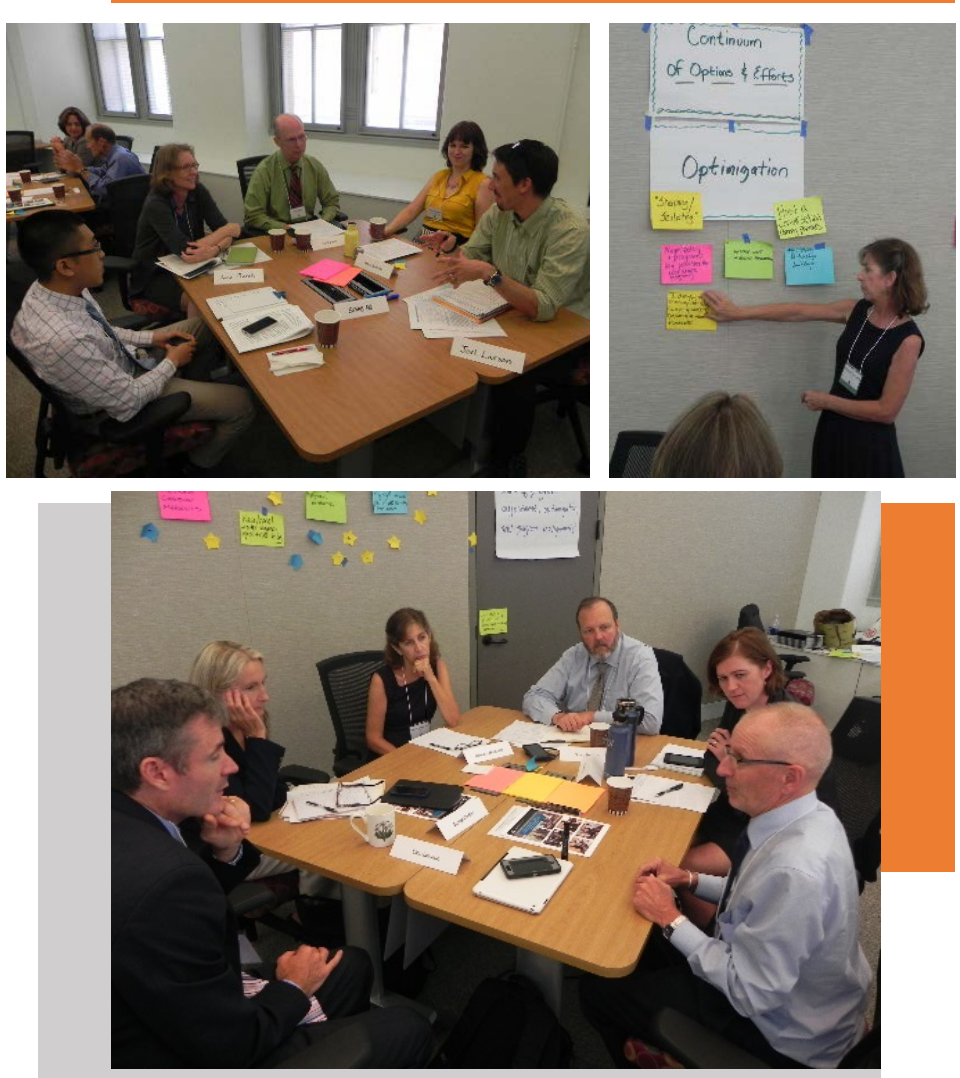

\section{Scale of action needed to improve USDA programs to support GHG mitigation in the Forest sector}

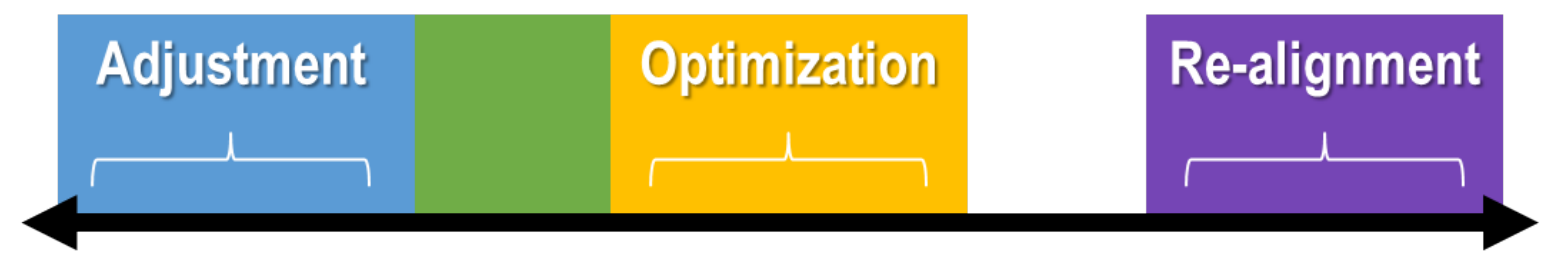

Figure 1: Continuum of effort posed to USDA program managers at the Finding GHG Mitigation Opportunities workshop. 
1. Develop a baseline inventory of where carbon is explicitly included in USDA Programs.

A comprehensive synthesis of where carbon is and is not explicitly included would be a good precursor to other suggested changes (e.g. \# 4 Incorporating carbon into Conservation Practice Standards). Components of this synthesis are already in progress through the USDA Building Block initiative and within some individual USDA programs.

2. Increase the exchange of knowledge between science and land management communities to create more "usable science" on mitigation.

Many of the science-based tools and documents on forest carbon sequestration are complex, difficult to use, and lack a centralized repository. They are therefore not easily accessible to the management community. Managers consequently may not have the information they need to make informed decisions on carbon sequestration.

\section{Finalize an Agricultural Adaptation} Workbook that walks managers through climate-informed decision-making.

The Adaptation Workbook created by the Northern Institute of Applied Climate Science has been a successful model for leading natural resource managers through an approach for considering climate change in forest management decisions. The Northeast Climate Hub is modifying this workbook for agricultural decision-making. The concepts behind this approach could be incorporated into existing handbooks such as the National Conservation Practice Standards Handbook.

\section{CONTINUUM OF EFFORT: PROGRAM ADJUSTMENT}

Program(s) impacted: All

\section{What is needed to make this happen?}

- The USDA Climate Program Office creates a report every three years and could include this as a component.

- Synchronize efforts within individual programs: USDA National Institute of Food and Agriculture (NIFA) is doing a climate analysis of their entire portfolio, and the new Regional Conservation Partnership Program (RCPP) could include climate change as a resource concern.

\section{CONTINUUM OF EFFORT: PROGRAM ADJUSTMENT}

Program(s) impacted: All; the USDA Climate Hubs could serve as the center for disseminating information.

What is needed to make this happen?

- Fund applied research

- Create materials, synthesis documents, and tools in user-friendly formats.

- Develop libraries of best management practices.

- Make materials more centralized and accessible.

- Provide opportunity for stakeholder input on information needs for GHG mitigation.

\section{CONTINUUM OF EFFORT: PROGRAM ADJUSTMENT}

Program(s) impacted: NRCS Conservation Stewardship Program (CSP), NRCS Environmental Quality Incentives Program (EQIP)

\section{What is needed to make this happen?}

- Approve, publish, and digitize the workbook for broader use.

- Expand the regional scope to cover areas outside of the Midwest and Northeast.

- Integrate this decision-making process into existing handbooks, reference guides, and standard processes. 
4. Incorporate carbon sequestration and storage into relevant USDA program guidance, such as NRCS conservation practice standards and USFS State and Private Forestry programs.

NRCS Conservation Practice Standards (CSP's) already include some practices that have benefits. However, an official decision to promote carbon sequestration and storage in CSP's would be a simple demonstration of priority and would permeate many USDA programs affecting on-theground management practices. This could be done using the existing state of knowledge on this topic without requiring further quantification and technical analyses.

5. For all Building Blocks, run an analysis on enhanced GHG reduction and carbon sequestration goals for 2025 .

The GHG reduction targets for the current 10 USDA Building Blocks are based on (and constrained by) funding levels, authorities, and existing partnerships. Rigorously developed, but larger impact targets could be useful for expanding and launching new partnerships, initiating private-sector partnerships, and making a case for enhanced investment.

\section{CONTINUUM OF EFFORT:}

PROGRAM ADJUSTMENT/OPTIMIZATION

Program(s) impacted: All NRCS Programs and some USFS Programs:

- NRCS Conservation Technical Assistance Program

- NRCS Conservation Stewardship Program (CSP)

- NRCS Environmental Quality Incentives Program (EQIP)

- USFS Forest Stewardship Program

- Forest Stand Improvement (Practice 666)

\section{What is needed to make this happen?}

- Coordination and technical assistance between WO and field offices to help agency staff apply carbonrelated criteria to project evaluation.

\section{CONTINUUM OF EFFORT:}

PROGRAM ADJUSTMENT/OPTIMIZATION

Program(s) impacted: Multiple

\section{What is needed to make this happen?}

- The re-evaluation of GHG reduction targets is currently in process. New targets could be included in the "USDA Building Blocks: Goals and Key Actions" table on page 4 of the USDA Building Blocks for Climate Smart Agriculture and Forestry Implementation Plan and Progress Report. 
6. Increase the presence of forestry and land management in competitive research.

Competitive research funding does not always address applied forestry questions. Increasing and/or redirecting USDA funding to applied forestry research would help address science gaps that are limiting implementation of greenhouse gas mitigation in the forest sector, and create clear linkages between large-scale forestry actions and expected carbon responses. It would also allow agencies to work with one another to leverage existing resources and prevent duplication of efforts.

\section{CONTINUUM OF EFFORT:}

PROGRAM OPTIMIZATION

\section{Program(s) impacted}

- USDA Agriculture and Food Research Initiative (AFRI - currently focused heavily on food production, could expand funding focus)

- Mclntire Stennis

- Forest Service Research \& Development, Forest Products Lab

- USDA Climate Hubs (outlet for delivering information).

\section{What is needed to make this happen?}

- Agencies (e.g. USFS, NIFA) need to work together to jointly define the questions that need to be addressed in the forest realm, and decide which questions each agency will address.

- Focus more heavily on applied research.

- NIFA can include forestry in their RFA's

\section{CONTINUUM OF EFFORT: PROGRAM OPTIMIZATION} numbers.

Many USDA stakeholders and partners may be unaware of the carbon connections and benefits provided by their own conservation priorities. Available information on this could be collected and developed into a format that is easy to communicate to a variety of audiences and to display spatially. These pieces could help translate information to policymakers, identify restoration and conservation needs at multiple scales, set administrative or policy targets, and communicate needs to stakeholders. These data could also contribute to other reporting efforts, such as The U.S. Agriculture and Forestry Greenhouse Gas Inventory and the Resources Planning Act Assessment. 


\section{Make carbon sequestration a more explicit objective of forest management.}

Sending a clear signal on agency direction and policy regarding forest carbon could help ensure that carbon considerations more clearly influence forest management and project design decisions. It could also create a positive tension within USDA to drive the demand for more science on management practices that positively affect carbon storage and sequestration. It could help encourage 'no regrets' strategies with clear carbon benefits, for example re-establishing forests on burned lands.

\section{Use NRCS and USFS projects as} demonstrations of a climate-informed management approach.

Joint projects could help provide innovative, onthe-ground forest management examples of carbon sequestration and storage and climate change adaptation. It would also serve as a way to provide examples of agency collaboration and leverage funding from varied sources.

\section{CONTINUUM OF EFFORT:}

PROGRAM OPTIMIZATION

Program(s) impacted: Forest management practices:

- Reforestation

- Fuel management (prescribed fire and wildfire)

What is needed to make this happen?

- Increased emphasis in agency direction and policy

- Increased emphasis in state and local plans

- A statement from the Secretary or Chief

- Increased investment in science connecting forestry actions to sequestration.

\section{CONTINUUM OF EFFORT:}

\section{PROGRAM OPTIMIZATION}

Program(s) impacted: Forest management practices:

- Two Chiefs' Joint Landscape Restoration Partnership

- Regional Conservation Partnership Program (RCPP)

What is needed to make this happen?

- Add carbon sequestration to project selection criteria

- Solicit examples from funded projects. 
10. Develop a better understanding of the relationship between climate and forest soil carbon.

There is limited understanding of below-ground carbon dynamics in forests, and forest carbon pools in the soil are only grossly estimated. More research on this topic could help to identify opportunities and areas for greenhouse gas mitigation and best management practices related to soil carbon. This would assist the US in its ability to meet current goals related to carbon sequestration and storage.

\section{Engage third-party market opportunities via cost share.}

Carbon markets could provide opportunities for USDA to partner with the private sector to prioritize carbon sequestration and storage. There may be opportunities to bring in third parties and attract conservation financing with the context of cost share and acquisition grants. This could tie into GHG mitigation efforts through the Clean Power Plan, and help incentivize working forest lands to be well-managed.

\section{Develop a "no net forest loss" policy.}

Although acknowledged as a significant realignment, embracing a national policy of 'keeping forests as forests' could provide a simple message that would engage multiple agencies in forest-sector GHG mitigation, including Housing and Urban Development, Department of Transportation, the Environmental Protection Agency, Department of Defense, and others. Forest presence would be easier to measure and track than forest carbon, and such a policy would allow flexibility in how forests are replaced (e.g. with urban canopy). It would also connect public and private sectors, and could tie in with state and local efforts on maintaining forest cover.

\section{CONTINUUM OF EFFORT:}

\section{PROGRAM REALIGNMENT}

Program(s) impacted: Forest Soil Health Assessment

What is needed to make this happen?

- Increased research of forest soils

- Programs dedicated to soil health in forests

CONTINUUM OF EFFORT: PROGRAM REALIGNMENT

Program(s) impacted: All

What is needed to make this happen?

- Decreasing market uncertainty

- Difficulty measuring success.

- Lowering transaction costs without regulatory overkill.

\section{CONTINUUM OF EFFORT:}

\section{PROGRAM REALIGNMENT}

Program(s) impacted: All

What is needed to make this happen?

- Executive leadership (e.g. secretarial order)

- Convening, facilitation, and cooperation by the USDA and Forest Service.

- Changes to certain laws.

- Extensive interagency discussion and coordination. 


\section{INTEGRATION OF THEMES BETWEEN WORKSHOPS $1 \& 2$}

The Finding USDA Programmatic GHG Mitigation Opportunities workshop built on the ideas and suggestions generated by the initial Perspectives from the Field workshop, so naturally several common themes were apparent. Each listed suggestion is explained in more detail in the Workshop sections.

1. Define the carbon connections and management goals within USDA programs and communicate these effectively.

Both workshops stressed the importance of providing clear guidance and specific goals relative to forest carbon storage and sequestration. This would send a clear signal to field practitioners on how the USDA is prioritizing forest-sector greenhouse gas mitigation, help define targets, and outline clear actions that can be taken to enhance sequestration and storage. USDA program leads and representatives built on comments from the Perspectives from the Field workshop to develop several suggestions on how to do this, including:

a. Make carbon sequestration a more explicit objective of forest management, sending a clear signal on agency direction.

b. Develop a baseline inventory of where carbon is explicitly included in USDA Programs.

c. For all Building Blocks, run an analysis on enhanced GHG reduction and carbon sequestration goals for 2025.

d. Incorporate carbon sequestration and storage into relevant USDA program guidance, such as NRCS Conservation Practice Standards and USFS State and Private Forestry programs.

e. Develop a 'No net forest loss' policy.
2. Incentivize and develop science-supported guidance on reducing GHG emissions and increasing carbon sequestration in the field.

Practitioners during the Perspectives from the Field workshop stressed the need for more scientificallysupported tools and guidance to help them enhance carbon benefits in on-the-ground projects. This sentiment was strongly echoed in the Finding USDA Programmatic GHG Mitigation Opportunities workshop, where many program leads and representatives developed suggestions for supporting science that directly informs forest-sector GHG mitigation:

a. Increase the exchange of knowledge between science and land management communities to create more "usable science" on mitigation.

b. Increase the presence of forestry and land management in competitive research.

c. Finalize an Agricultural Adaptation Workbook that walks managers through climate-informed decision-making.

d. Incorporate carbon sequestration and storage into relevant USDA program guidance, such as NRCS Conservation Practice Standards and USFS State and Private Forestry programs.

e. Develop a better understanding of the relationship between climate and forest soil carbon. 
3. Develop communication tools and policies to support public-private partnerships on carbon management.

Participants in both workshops widely recognized the need to engage non-USDA partners and the private sector in forest-based GHG mitigation. Forming partnerships could help to leverage outside conservation funding, increase efficiencies, and increase the likelihood of reaching or exceeding carbon goals.

The final list of USDA program suggestions frequently included collaboration between federal agencies, however there were a few that focused more specifically on the private sector. These included approaches ranging from creating communications elements that resonate with private stakeholders, to encouraging market-based incentives and policy changes:

a. Develop communications pieces that link conservation needs with carbon numbers.

b. Engage third-party market opportunities via cost share.

c. Develop a 'No net forest loss' policy.
4. Encourage innovation and demonstrations.

There are many opportunities for innovative approaches and partnerships when it comes to forestsector GHG mitigation, and participants in Perspectives from the Field did some initial brainstorming on potential ways to encourage this, ranging from better integrating academia and external partners, to capitalizing on the long-term land holdings and partnerships to create forest carbon demonstration sites at National Forests (see Workshop 1 section).

In Finding USDA Programmatic GHG Mitigation Opportunities, USDA program leads and representatives centered in on a suggestion for using existing collaborative NRCS and USFS programs to demonstrate climate and carbon-informed management, for example through the Two Chiefs' Joint Landscape Restoration Partnership and the Regional Conservation Partnership Program (RCPP):

a. Use NRCS and USFS projects as demonstrations of a climate-informed management approach. 


\title{
THIS WORK WAS MADE POSSIBLE BY SUPPORT FROM:
}

\author{
The United States Department of Agriculture: \\ Climate Change Program Office \\ Climate Hubs \\ Forest Service
}

The Trust for Public Land

The Chicago Field Museum kindly provided a venue and logistical support for the Perspectives from the Field Workshop 1.

Special thanks to the workshop participants for their valuable time and insights.

\section{RECOMMENDED CITATION:}

Northern Forests Climate Hub. 2016. Finding Opportunities within USDA Programs to Reduce Greenhouse Gas Emissions and Increase Carbon Sequestration. Report NFCH-1. Houghton, MI: U.S. Department of Agriculture, Climate Hubs. 17 p.

In accordance with Federal civil rights law and U.S. Department of Agriculture (USDA) civil rights regulations and policies, the USDA, its Agencies, offices, and employees, and institutions participating in or administering USDA programs are prohibited from discriminating based on race, color, national origin, religion, sex, gender identity (including gender expression), sexual orientation, disability, age, marital status, family/parental status, income derived from a public assistance program, political beliefs, or reprisal or retaliation for prior civil rights activity, in any program or activity conducted or funded by USDA (not all bases apply to all programs). Remedies and complaint filing deadlines vary by program or incident.

Persons with disabilities who require alternative means of communication for program information (e.g., Braille, large print, audiotape, American Sign Language, etc.) should contact the responsible Agency or USDA's TARGET Center at (202) 720-2600 (voice and TTY) or contact USDA through the Federal Relay Service at (800) 877-8339. Additionally, program information may be made available in languages other than English.

To file a program discrimination complaint, complete the USDA Program Discrimination Complaint Form, AD-3027, found online at http://www.ascr.usda.gov/complaint_filing_cust.html and at any USDA office or write a letter addressed to USDA and provide in the letter all of the information requested in the form. To request a copy of the complaint form, call (866) 632-9992. Submit your completed form or letter to USDA by: (1) mail: U.S. Department of Agriculture, Office of the Assistant Secretary for Civil Rights, 1400 Independence Avenue, SW, Washington, D.C. 20250-9410; (2) fax: (202) 690-7442; or (3) email: program.intake@usda.gov (link sends e-mail).

USDA is an equal opportunity provider, employer and lender. 